\title{
Erratum
}

Diabetes Metab J 2021;45:796

https://doi.org/10.4093/dmj.2021.0239

pISSN 2233-6079 · eISSN 2233-6087

Erratum: Figure Correction

\section{Epidemiology, Pathophysiology, Diagnosis and Treatment of Heart Failure in Diabetes}

Jin Joo Park

Cardiovascular Center, Division of Cardiology, Department of Internal Medicine, Seoul National University Bundang Hospital, Seoul National University College of Medicine, Seongnam, Korea

Diabetes Metab J 2021;45:146-157. https://doi.org/10.4093/dmj.2020.0282

There were word errors in the Fig. 1.

- "Myocardial ischemia smoking" in the middle of Fig. 1 was wrong. The correct word is "Myocardial ischemia."

- "Dyslipidaemia" in the middle of Fig. 1 was misspelled. The correct word is "Dyslipidemia."

We apologize for any inconvenience that this may have caused.
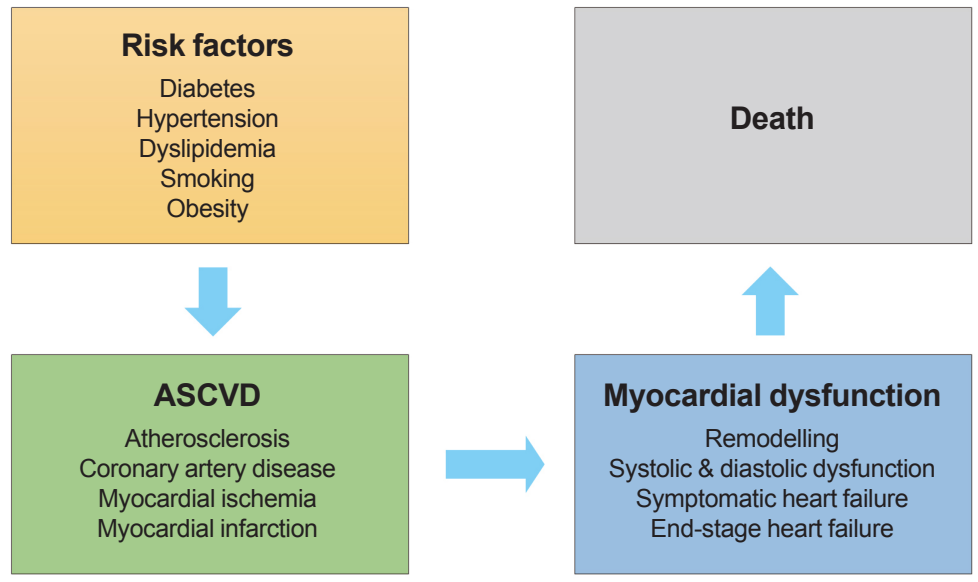

Fig. 1. The cardiovascular disease continuum. ASCVD, atherosclerotic cardiovascular disease.

This is an Open Access article distributed under the terms of the Creative Commons Attribution Non-Commercial License (https://creativecommons.org/licenses/by-nc/4.0/) which permits unrestricted non-commercial use, distribution, and reproduction in any medium, provided the original work is properly cited. 